Journal Of Al Azhar University Engineering Sector

Vol. 13, No. 48, July 2018, $884-893$

\title{
PERFORMANCE OF DIAPHRAGM WALL IN COHESIVE SOILS UNDER STATIC AND SEISMIC LOADING CONDITIONS
}

\author{
Tarek, M. F, Bahr, M. A. , Hassan, A. A and Hemeida, A. M. \\ Department of Civil Engineering, Al-Azhar University , Cairo, Egypt
}

\begin{abstract}
:
The extension of the underground and infrastructure projects in urban areas is often linked with the design and construction of complex geotechnical structures. Deep excavations are required to meet the demand, and in many cases, excavation sites are in close proximity to existing structures and facilities. A major concern in these excavations is to control the lateral wall deflections and the ground surface settlements. As a result, understanding and being able to predict the performance of deep excavations is an important issue for geotechnical engineers. A 3D numerical analysis can be valuable to assess the behavior of the earth-retaining structure and the surrounding soil. In this research, the main objective is to study the combined influence of the geometric configuration and the consistency of the cohesive soil on the performance of the diaphragm walls and surrounding soil under static and seismic conditions. This study comprises 3D numerical analyses performed for different configurations of deep excavation in cohesive soil supported by diaphragm wall. The results present the main impacts of the investigated parameters on the behavior of the earth-retaining structure under static and seismic conditions.
\end{abstract}

\section{KEYWORDS : 3D, NUMERICAL ANALYSIS, DEEP EXCAVATION, DIAPHRAGM WALL, SEISMIC.}

\section{INTRODUCTION}

The extension of the underground and infrastructure projects in urban areas is often linked with the design and construction of complex geotechnical structures. A significant concern in deep excavations is to control the lateral wall deflections and ground surface settlements. Thus, considering the possible measures for understanding and assessing the behaviour of deep excavations is a vital matter for geotechnical engineers. The trend of ground surface deformations has been previously studied with the objective of identifying general pattern and magnitude of ground surface deformations associated with deep excavation projects. Goldberg et al. [1]; Peck [2]; and Clough \& O'Rourke [3] have correlated the subsurface conditions of several deep excavations with field measurements. Generally, the caused ground surface deformations are mainly related to the subsurface conditions. Ou et al. [4] conducted a three-dimensional numerical analysis for simulating a deep excavation retained by diaphragm wall with cross walls. Both the observed and computed wall deflections for the considered project were studied. The researchers found that, for a realistic simulating of the deep excavation system, a threedimensional numerical analysis is required. The influence of the excavation corner on the behavior of a diaphragm wall is numerically investigated by Law et al. [5]. They found that, it is important to take into consideration the geometrical or corner effect when evaluating the performance of excavations. Wood [6] examined the dynamic response of homogeneous linear elastic soil trapped in between two rigid walls connected to a rigid base, providing an analytical solution. The seismic response of retaining walls is investigated by Kitsis et al. [7] who concluded that in the design of massive and rigid earth retaining walls, it is reasonable and warranted to assume a synchronous action of the maximum values of wall inertia and seismic earth thrust. 
The current research investigates the combined effect of varying the geometric configuration of a deep excavation and the consistency of the cohesive soil on the performance of diaphragm wall and surrounding soil under static and seismic conditions.

\section{MODELLED DEEP EXCAVATION}

The height of final excavation level $(\mathrm{H})$ is taken as $10 \mathrm{~m}$ with total width of the excavation (B) is 20 $\mathrm{m}$. The excavation dimensions on plan are varied between square excavation $(\mathrm{L} / \mathrm{B}=1)$ and rectangular excavation $(\mathrm{L} / \mathrm{B}=3)$. Medium and stiff cohesive soil deposits are considered with the ground water level is at $3 \mathrm{~m}$ depth from the natural ground surface. All the above-mentioned parameters are investigated under static and seismic conditions. The 3-dimensional finite element program PLAXIS is adopted in this study with the Hardening Soil model. To perform finite element calculations, the geometry has to be divided into elements. A composition of finite elements is called finite element mesh. PLAXIS 3D Program allows for a fully automatic generation of finite element meshes. Figure (1) illustrates the 3D mesh layout of the proposed finite element model.

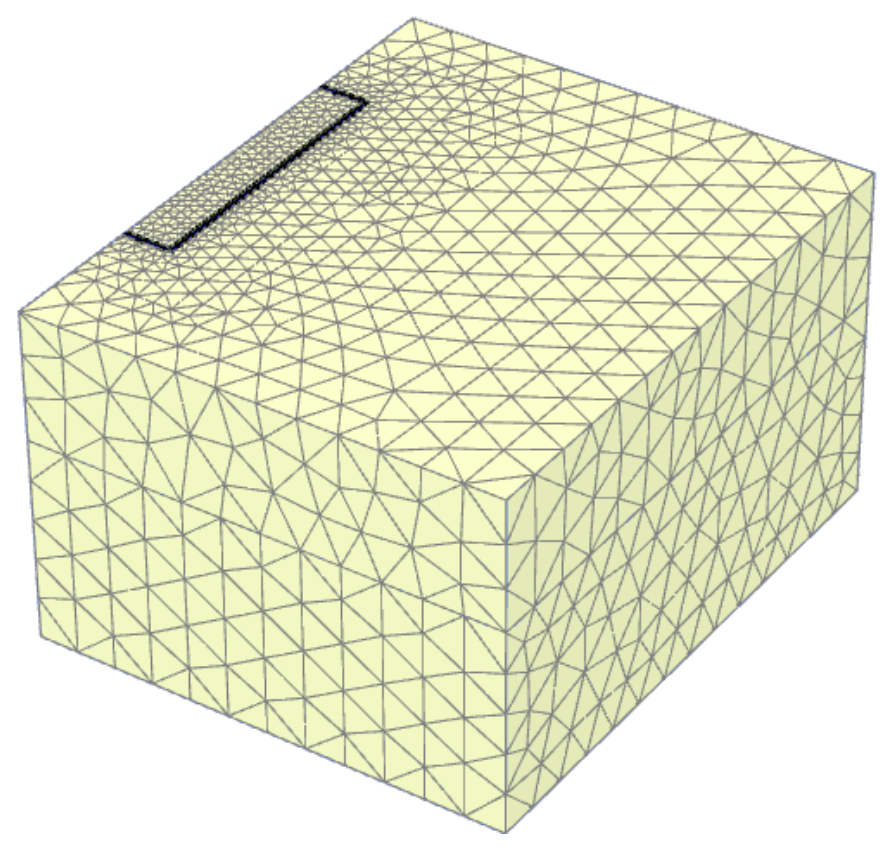

Figure (1): 3D mesh layout of the proposed finite element model

Figure (2) shows plan of the excavation site for the proposed study, while Figure (3) depicts the cross section of the proposed deep excavation system. Two rows of supports are used. Medium and stiff cohesive soil deposits are considered. The parameters of the proposed cohesive soils are presented in Table (1). $\mathrm{E}_{50}$ is set equal to $\mathrm{E}_{\mathrm{oed}}$, and $\mathrm{E}_{\mathrm{ur}} / \mathrm{E}_{50}=3$. The excavation dimensions on plan are varied between square excavation $(\mathrm{L} / \mathrm{B}=1)$ and rectangular excavation $(\mathrm{L} / \mathrm{B}=3)$. The penetration depth of the wall is determined to satisfy the overall stability requirements. For the seismic loading condition, the considered values of Peak Ground Acceleration (PGA) are in range of $0.1 \mathrm{~g}$ to $0.3 \mathrm{~g}$.

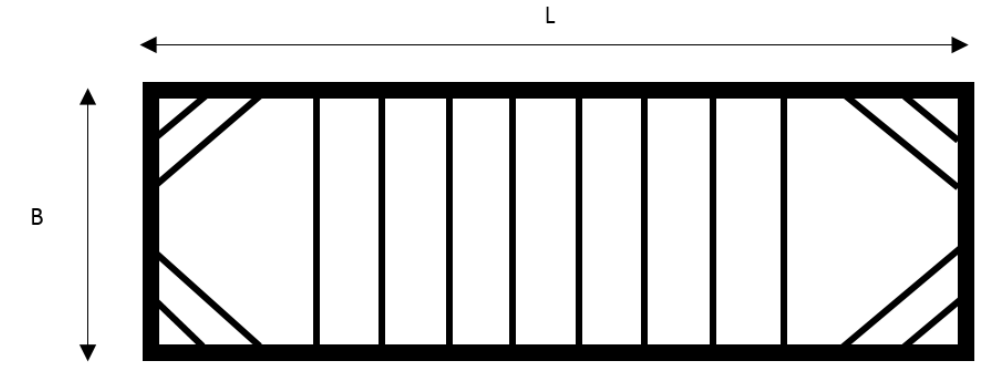

Figure (2): Plan of the excavation site for the proposed study 


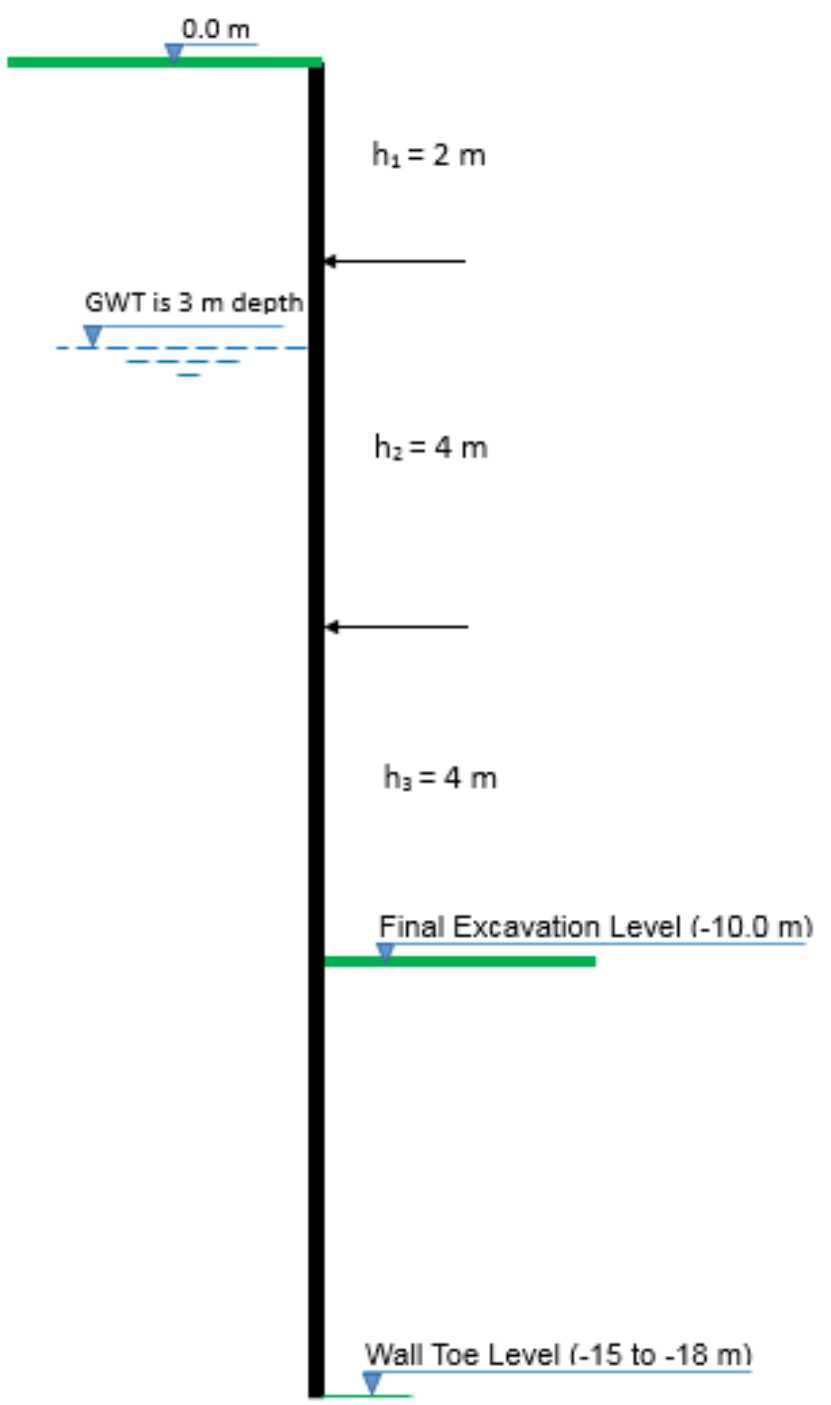

Figure (3): Cross section of the considered deep excavation system

Table 1: Parameters of the cohesive soil deposits adopted in the current study

\begin{tabular}{|c|c|c|c|c|}
\hline Consistency & $\mathrm{C}_{\mathrm{u}}(\mathrm{kPa})$ & $\mathrm{E}(\mathrm{MPa})$ & $\begin{array}{c}\text { Dry Unit Weight } \\
\left(\mathrm{kN} / \mathrm{m}^{3}\right)\end{array}$ & $\begin{array}{c}\text { Saturated Unit Weight } \\
\left(\mathrm{kN} / \mathrm{m}^{3}\right)\end{array}$ \\
\hline Stiff & 100 & 10 & 17 & 20.7 \\
\hline Medium & 50 & 6 & 15 & 19.4 \\
\hline
\end{tabular}

\subsection{FOR SQUARE EXCAVATION (L/B = 1)}

Figure (4) presents the wall lateral displacement profiles under static and seismic conditions of the square excavation $(\mathrm{L} / \mathrm{B}=1)$. Under static condition, the maximum lateral displacements of the wall are approximately ranging between $38 \mathrm{~mm}$ and $23 \mathrm{~mm}$ for medium and stiff clays, respectively. While, under seismic condition, the maximum wall displacements are in the range of $50 \mathrm{~mm}$ and 88 $\mathrm{mm}$ for medium clay at peak ground acceleration (PGA) oscillating between $0.1 \mathrm{~g}$ and $0.3 \mathrm{~g}$.

For stiff clay, the maximum lateral displacements of the wall under seismic condition are ranging between $30 \mathrm{~mm}$ and $49 \mathrm{~mm}$ at peak ground acceleration (PGA) oscillating between $0.1 \mathrm{~g}$ and $0.3 \mathrm{~g}$.

It is noticed that the maximum wall lateral displacements for the static condition occur at a depth of about 9 to $10 \mathrm{~m}$ below ground surface, while it is at 10 to $13 \mathrm{~m}$ depth for the seismic condition. 


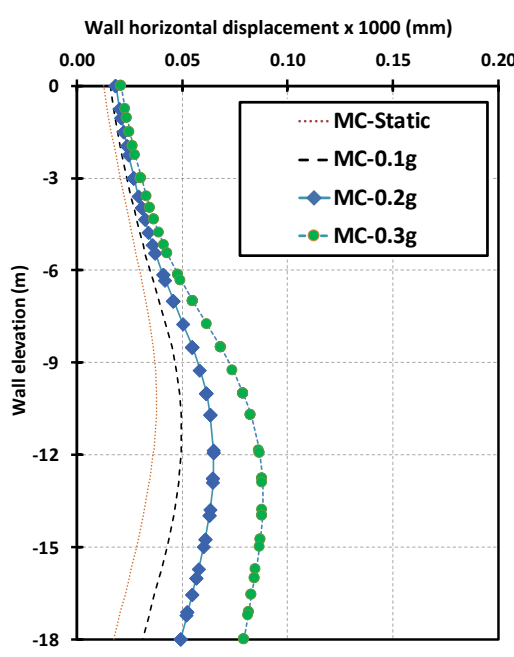

(a)

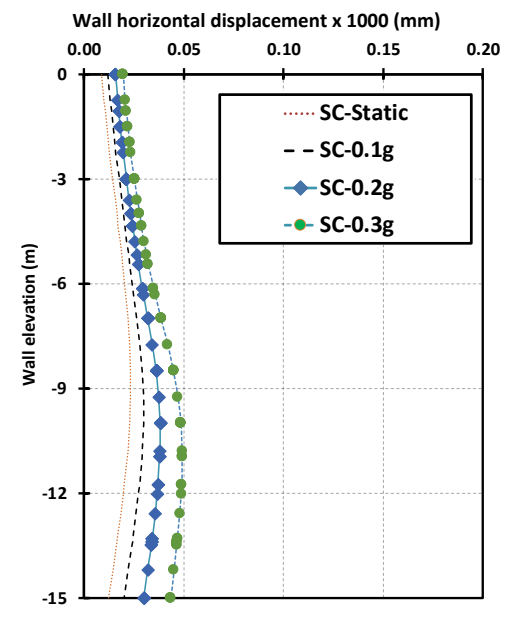

(b)

Figure (4): Plot of wall displacement profiles of (a) medium clay and (b) stiff clay deposits under static condition against range of wall displacements expected to occur under seismic condition (PGA=0.1g to $0.3 \mathrm{~g})$

Figure (5) shows a series of profiles for the ground surface settlements behind wall under static and seismic conditions of the square excavation $(\mathrm{L} / \mathrm{B}=1)$. At static condition, the maximum vertical displacements of ground surface are approximately ranging between 28 $\mathrm{mm}$ and $13 \mathrm{~mm}$ for medium and stiff clays, respectively. At seismic condition, the maximum ground surface displacements of medium clay are in the range of $31 \mathrm{~mm}$ and $37 \mathrm{~mm}$ for peak ground acceleration (PGA) varying between $0.1 \mathrm{~g}$ and $0.3 \mathrm{~g}$. However, for stiff clay under seismic condition, the maximum ground surface displacements are in the range of $13.5 \mathrm{~mm}$ and $17 \mathrm{~mm}$ for peak ground acceleration (PGA) oscillating between $0.1 \mathrm{~g}$ and $0.3 \mathrm{~g}$. The maximum vertical displacements of ground surface occur approximately at a distance away from the wall of about $4 \mathrm{~m}$ to $6 \mathrm{~m}$ for static condition, while it is at $6 \mathrm{~m}$ to $13 \mathrm{~m}$ for seismic condition.
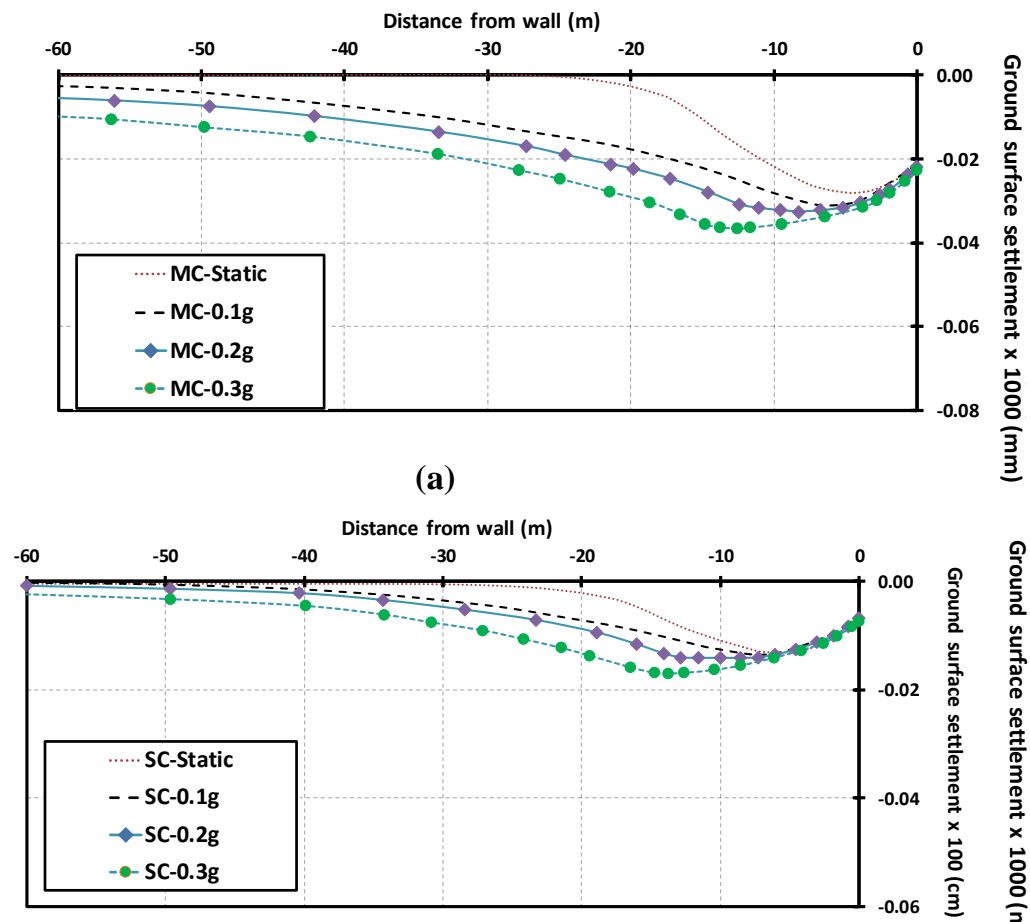

(b)

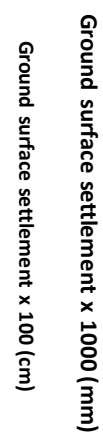

Figure (5): Plot of ground surface settlements profiles of (a) medium clay, and (b) stiff clay deposits under static condition against range of ground settlements expected to occur under seismic condition (PGA=0.1g to $0.3 g$ ) 


\subsection{For Rectangular Excavation $(\mathrm{L} / \mathrm{B}=3)$}

Figure (6) presents the wall lateral displacement profiles of medium clay for the cantilever stage of 3 $\mathrm{m}$ unsupported height. The maximum wall lateral displacements are at the wall top, and are approximately $22 \mathrm{~mm}, 54 \mathrm{~mm}, 107 \mathrm{~mm}$, and $201 \mathrm{~mm}$, for static, $P G A=0.1 \mathrm{~g}, 0.2 \mathrm{~g}$, and $0.3 \mathrm{~g}$, respectively. The normalized lateral displacements of the wall over the unsupported height $(3 \mathrm{~m})$ are about $0.7 \%, 1.8 \%, 3.6 \%$, and $6.7 \%$, for static, $\mathrm{PGA}=0.1 \mathrm{~g}, 0.2 \mathrm{~g}$, and $0.3 \mathrm{~g}$, respectively.

The wall lateral displacement profiles at the final stage of excavation are shown in Figure (7) for the rectangular excavation $(\mathrm{L} / \mathrm{B}=3$ ). For the static condition, the maximum lateral displacements of the wall are in the order of $68 \mathrm{~mm}$ and $35 \mathrm{~mm}$ for medium and stiff clays, respectively. However, for the seismic condition, the maximum wall displacements are ranging between $86 \mathrm{~mm}$ and $163 \mathrm{~mm}$ for medium clay at peak ground acceleration (PGA) varying between $0.1 \mathrm{~g}$ and $0.3 \mathrm{~g}$.

For stiff clay under seismic condition, the maximum lateral displacements of the wall are $45 \mathrm{~mm}$ and $80 \mathrm{~mm}$ at peak ground acceleration (PGA) oscillating between $0.1 \mathrm{~g}$ and $0.3 \mathrm{~g}$.

It is worth noting that the maximum wall lateral displacements occur at a depth of about 10 to $10.4 \mathrm{~m}$ below ground surface for the static condition, while it is at 11 to $13.3 \mathrm{~m}$ depth for the seismic condition.

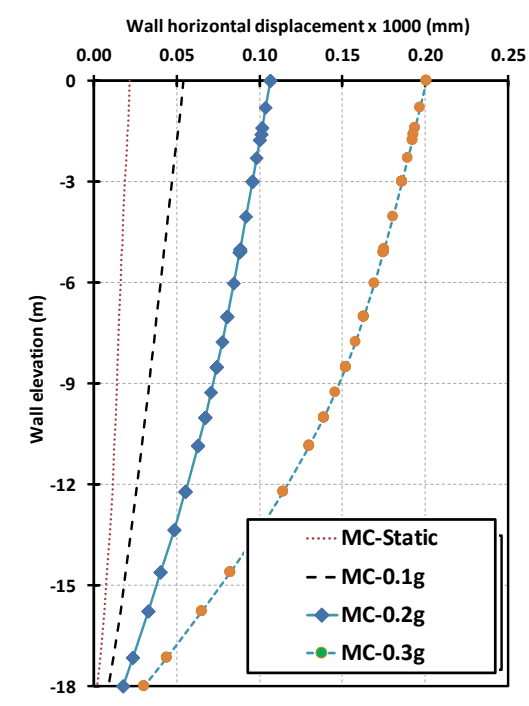

Figure (6): Plot of wall displacement profiles for the cantilever stage of $3 \mathbf{m}$ unsupported height for medium clay under static condition against range of wall displacements expected to occur under seismic

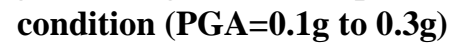

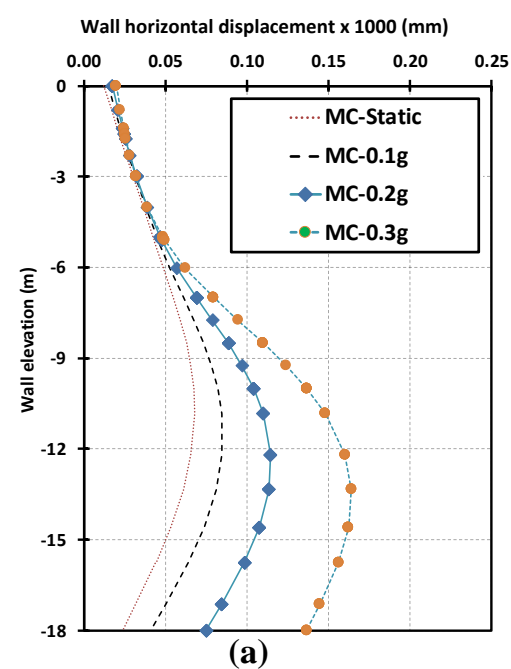

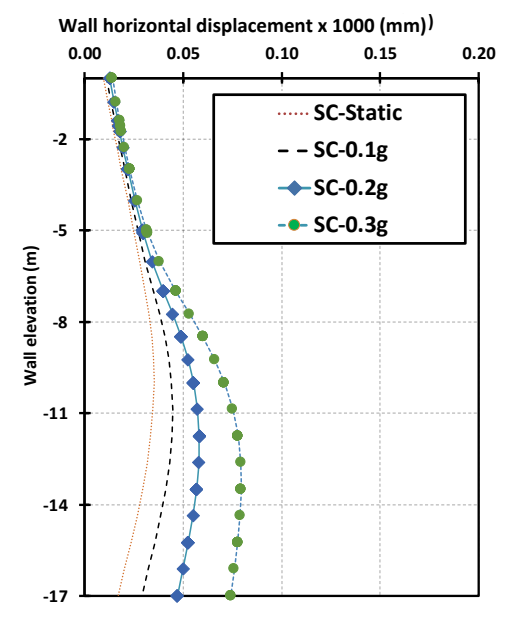

(b)

Figure (7): Plot of wall displacement profiles of (a) medium clay and (b) stiff clay deposits under static condition against range of wall displacements expected to occur under seismic condition (PGA=0.1g to 
Figure (8) shows the ground surface settlements behind wall under static and seismic conditions for the rectangular excavation $(\mathrm{L} / \mathrm{B}=3)$. Under static condition, the maximum vertical displacements of ground surface are approximately ranging between $51 \mathrm{~mm}$ and $23 \mathrm{~mm}$ for medium and stiff clays, respectively. Under seismic condition, the maximum ground surface displacements of medium clay are in the range of $55 \mathrm{~mm}$ and $78 \mathrm{~mm}$ for peak ground acceleration (PGA) varying between $0.1 \mathrm{~g}$ and $0.3 \mathrm{~g}$. However, for stiff clay under seismic condition, the maximum ground surface displacements are in the order of $24 \mathrm{~mm}$ and $33 \mathrm{~mm}$ for peak ground acceleration (PGA) ranging between $0.1 \mathrm{~g}$ and $0.3 \mathrm{~g}$. The maximum vertical displacements of ground surface occur approximately at a distance away from the wall of about $7 \mathrm{~m}$ for static condition, while it is at $9 \mathrm{~m}$ to $13 \mathrm{~m}$ for seismic condition.

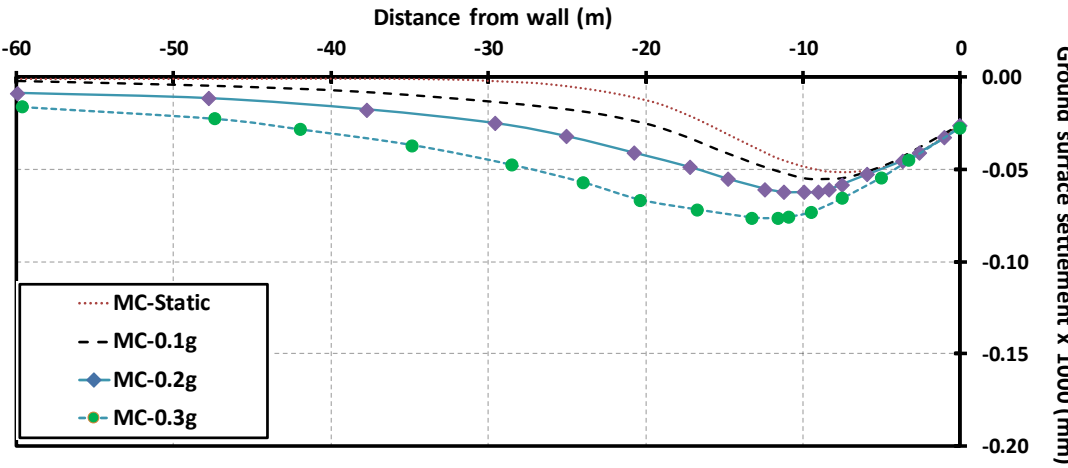

(a)

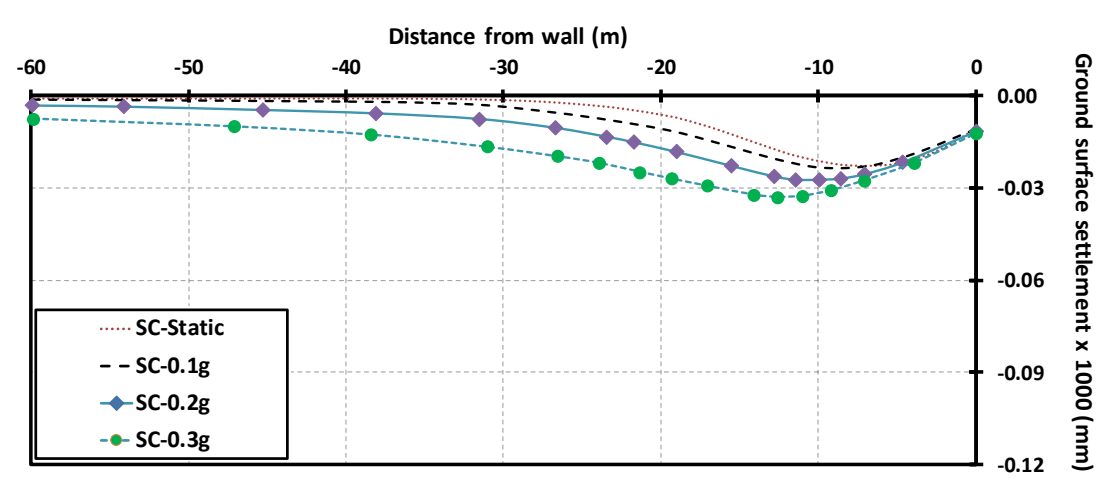

(b)

Figure (8): Plot of ground surface settlements profiles of (a) medium clay, and (b) stiff clay deposits under static condition against range of ground settlements expected to occur under seismic condition (PGA=0.1g to $0.3 g$ )

Figure (9) shows the wall bending moment diagrams of medium clay and stiff clay deposits under static and seismic conditions. For medium clay, the maximum wall bending moments are around 623, 700, 797, and $1100 \mathrm{kN} . \mathrm{m}$ for static, PGA=0.1g, $0.2 \mathrm{~g}$, and $0.3 \mathrm{~g}$, respectively. However, for stiff clay, the maximum wall bending moments are approximately $350,382,527$, and $714 \mathrm{kN} . \mathrm{m}$ for static, PGA $=0.1 \mathrm{~g}, 0.2 \mathrm{~g}$, and $0.3 \mathrm{~g}$ respectively. It is worth mentioning that applying the seismic condition on the retaining wall causes developing additional bending moment which should be considered, especially for the areas of high seismicity.

Figure (10) presents the distribution of maximum lateral wall displacements along the wall. For the static condition, the section at which the maximum wall lateral displacements occurred is at depth of $10-10.4 \mathrm{~m}$ below ground surface, while, the section is at depth of $11-13.3 \mathrm{~m}$ for the seismic condition. The wall deformations increase with increasing distance from the corner, however, there is a stationary point where the deformations are no longer increasing, which indicates that the corner stiffening effect is minimized beyond a certain distance from the corner. For medium clay, this stationary point is approximately at $30 \mathrm{~m}$ away from the corner, while it is about $20 \mathrm{~m}$ away from the corner for stiff clay. This finding is in relatively good agreement with Ahmad et al. [8] who studied the three-dimensional performance for one of Greater Cairo underground metro stations (Rod El-Farag 
Station), and reported that the three-dimensional corner effects extend to about $25 \mathrm{~m}$ from the corner, and beyond that point, the wall movement is no longer increasing.

It is worth noting that as the soil stiffness increases, the influence distance of the corner is decreased, and accordingly the stationary point becomes closer to the wall corner.

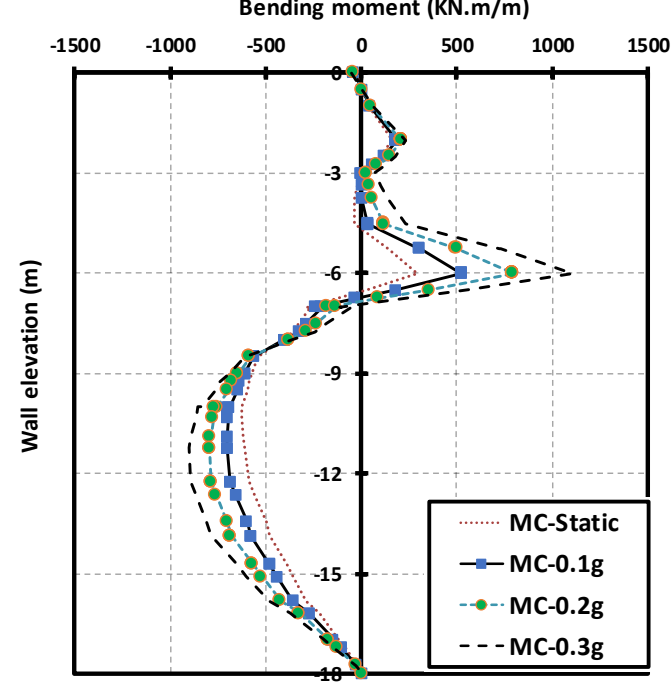

(a)

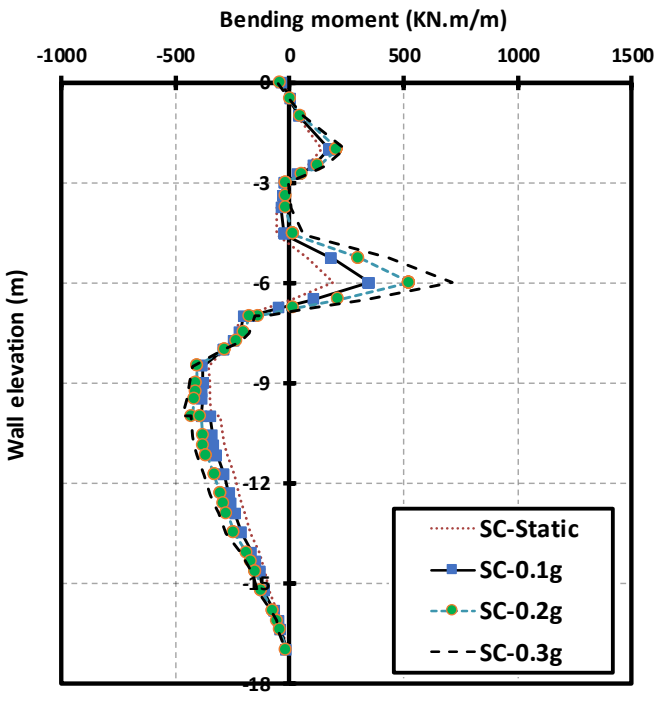

(b)

Figure (9): Plot of wall bending moment profiles of (a) medium clay, and (b) stiff clay deposits under static and seismic conditions (PGA=0.1g to $0.3 \mathrm{~g}$ )

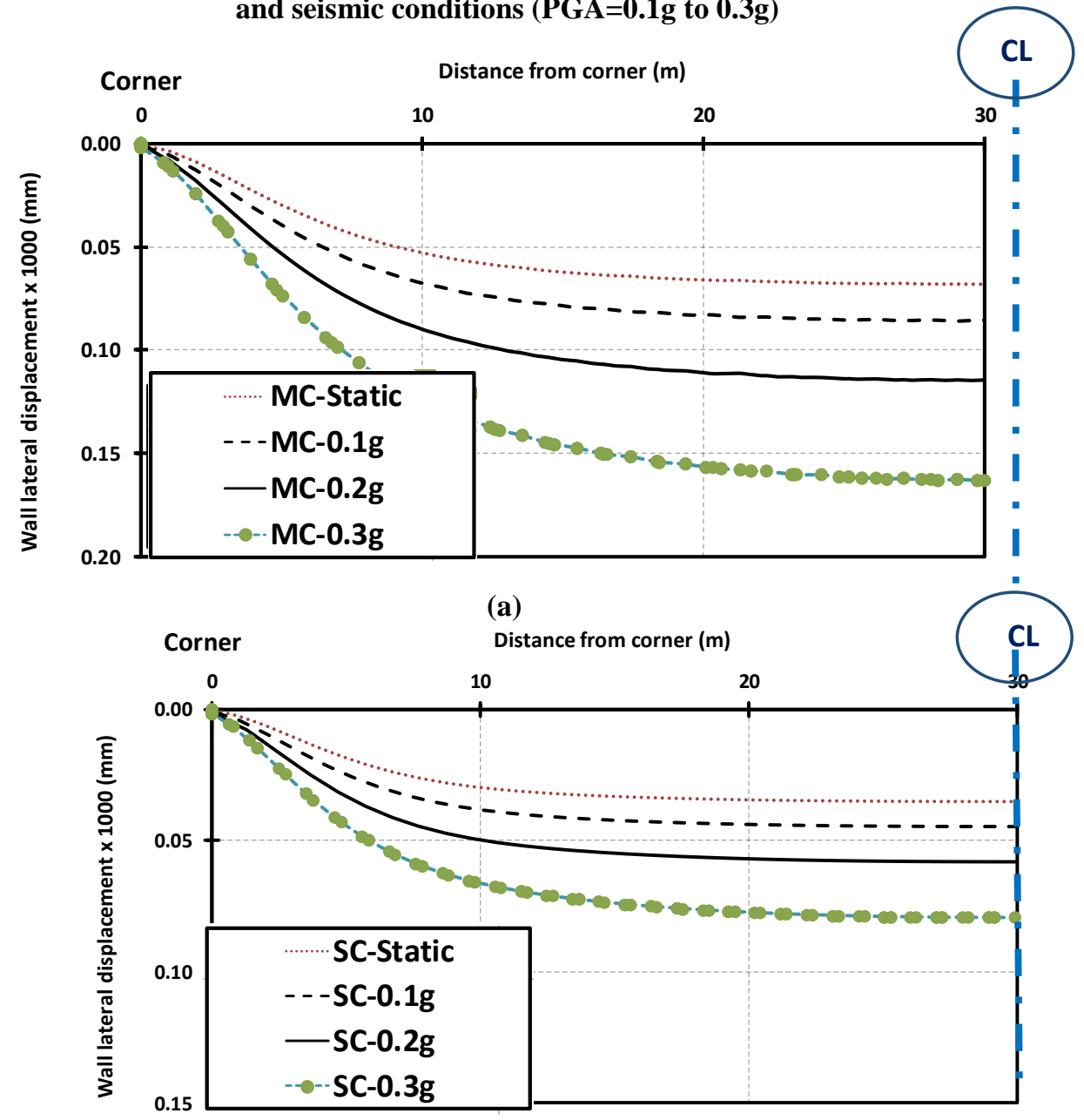

(b)

Figure (10): Distribution of maximum lateral displacements along the wall of (a) medium clay, and (b) stiff clay deposits under static and seismic conditions (PGA=0.1g to 0.3g) 


\section{NORMALIZED SUMMARY CHARTS}

Figure (11) and Figure (12) present the results of the current research plotted against measured ground surface settlements under static condition for several project sites collected by many researchers (e.g. Clough and O'Rourke [3]). Figures (11) \& (12) are adapted from the Canadian Foundation Engineering Manual [9], and AASHTO [10], accordingly. The results of the current study are plotted with the results of an additional case of excavation height equals $15 \mathrm{~m}$. It is noticed that the results of the numerical analyses for the stiff clays show relatively good agreement with the pattern of the measured deformations. The ground surface settlements of stiff clays are practically small and do not exceed $0.3 \%$ of the excavation depth. On the other hand, Figure (12) shows the results of the numerical analyses for the medium clays, at which the ground surface settlements are not exceeding $1.0 \%$ of the excavation depth.

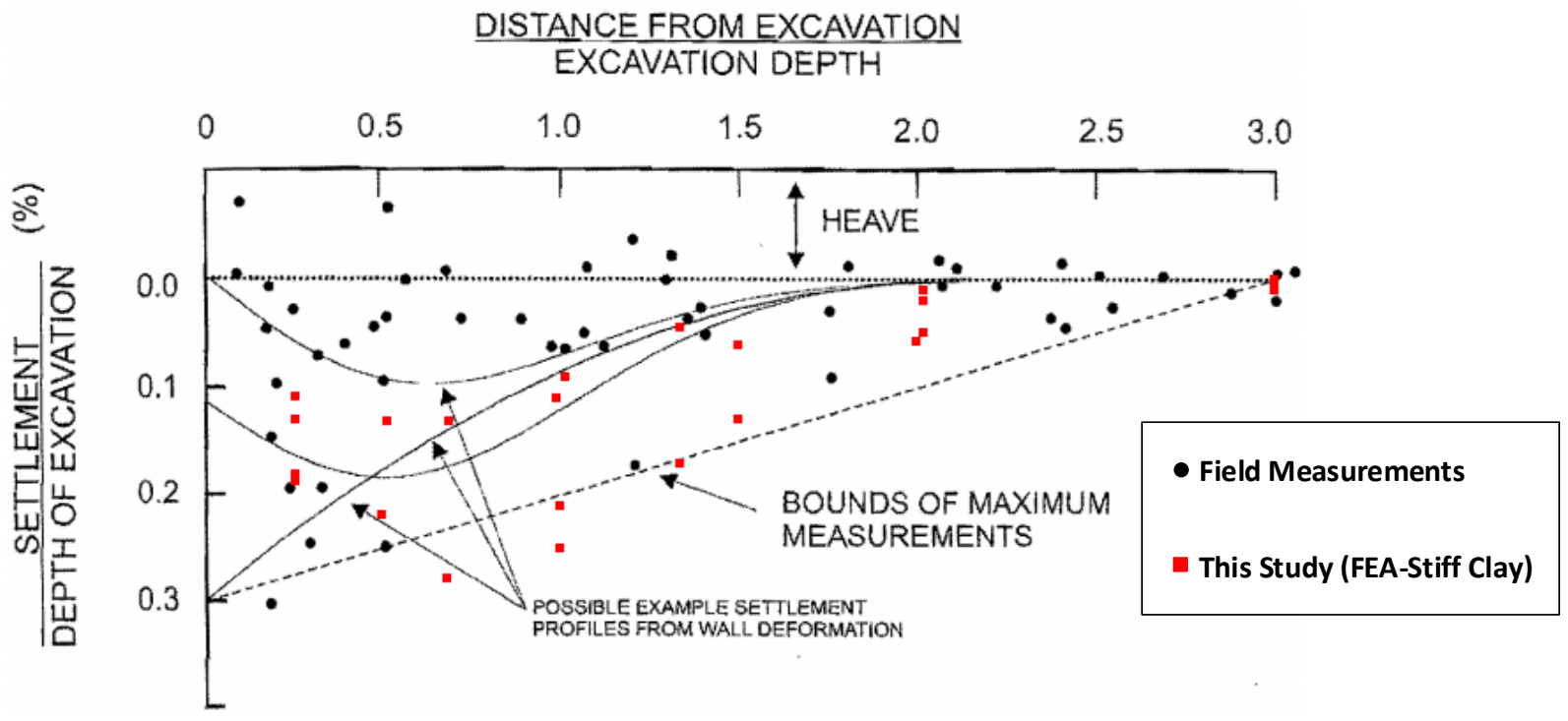

Figure (11): Summary of measured ground surface settlements adjacent to excavations in stiff clays against results of this current study (FEA-Stiff Clay)

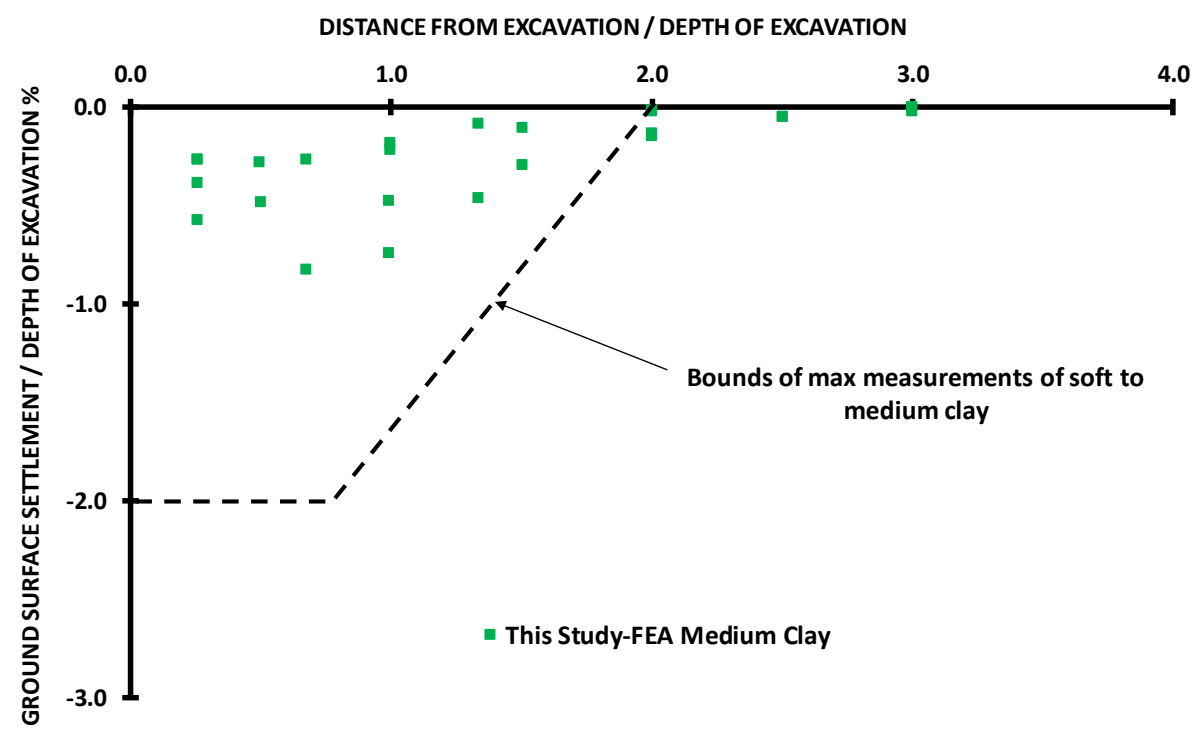

Figure (12): Summary of measured ground surface settlements adjacent to excavations in soft to medium clays against results of this current study (FEA-Medium Clay)

Figure (13) and (14) illustrate the maximum normalized lateral wall displacements and ground surface settlements for cohesive soil deposits under static and seismic conditions. The maximum normalized lateral wall displacements (as \% of excavation height) are in the 
average of $0.33 \% \& 0.7 \%$ for the static condition, $0.42 \% \& 0.88 \%$ for $\mathrm{PGA}=0.1 \mathrm{~g}, 0.52 \% \&$ $1.18 \%$ for $\mathrm{PGA}=0.2 \mathrm{~g}$, and $0.7 \% \& 1.67 \%$ for $\mathrm{PGA}=0.3 \mathrm{~g}$. The maximum normalized ground surface settlements (as \% of excavation height) are in the average of $0.2 \% \& 0.48 \%$ for the static condition, $0.21 \% \& 0.52 \%$ for $\mathrm{PGA}=0.1 \mathrm{~g}, 0.22 \% \& 0.59 \%$ for $\mathrm{PGA}=0.2 \mathrm{~g}$, and $0.26 \% \&$ $0.74 \%$ for $\mathrm{PGA}=0.3 \mathrm{~g}$.

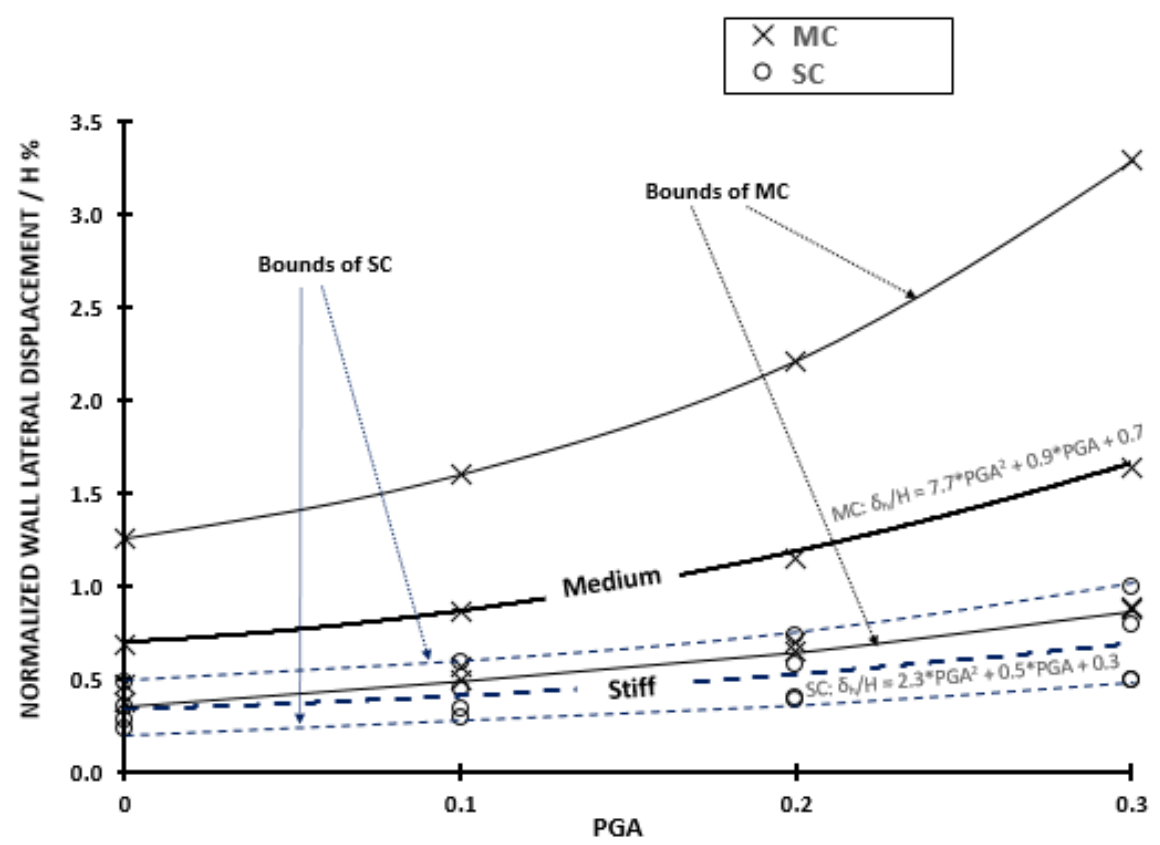

Figure (13): Plot of the maximum normalized lateral wall displacements for cohesive soil deposits under static and seismic conditions (PGA=0.1g to $0.3 \mathrm{~g}$ )

PGA

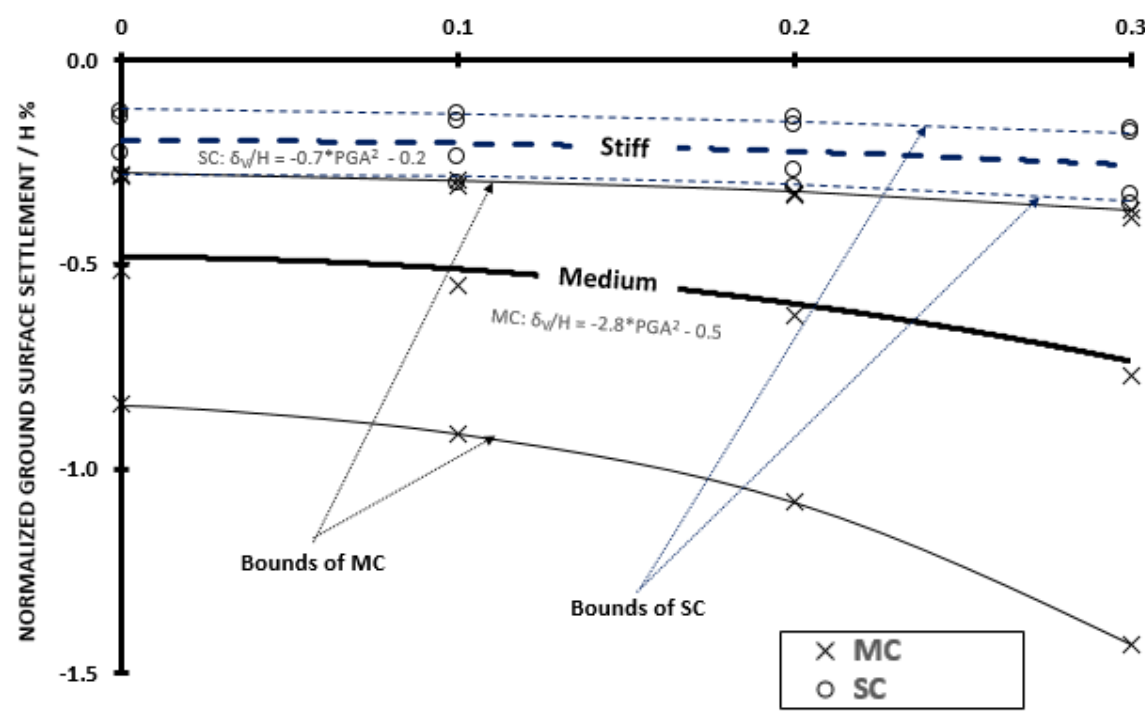

Figure (14): Plot of the maximum normalized ground surface settlements for cohesive soil deposits under static and seismic conditions (PGA=0.1g to $0.3 \mathrm{~g}$ )

\section{CONCLUSIONS}

The conclusions drawn from this research are summarized herein: 
1) Charts linking normalized wall displacements and ground surface settlements under static and seismic conditions are introduced.

2) Wide range of wall and ground surface movements should be anticipated when the seismic condition is employed, since it has a considerable influence on the behaviour of the wall and ground surface.

3) The wall and ground surface deformations of the seismic condition are larger than those of the static condition (at the final stage) by approximately average of $49 \%$ for medium clay, and average of $38 \%$ for stiff clay.

4) The wall and ground surface deformations of the medium clay are larger than those of the stiff clay by approximately average of $115 \%$ for static condition, and average of $132 \%$ for seismic condition.

5) The wall deformations increase with increasing distance from the corner, even so, the corner stiffening effect is minimized beyond a certain distance from the corner. For medium clay, this distance is approximately $30 \mathrm{~m}$ away from the corner, while it is about $20 \mathrm{~m}$ away from the corner for stiff clay.

\section{REFERENCES}

1. Goldberg, D.T., Jaworski, W.E., and Gordon, M.D., "Lateral Support Systems and Underpinning", Report FHWA-RD-75-128, Federal Highway Administration, vol. 1, Washington D.C., 1976.

2. Peck, R.B, "Deep Excavations and Tunneling in Soft Ground", Proc. $7^{\text {th }}$ International Conference on Soil Mechanics and Foundation Engineering, State of the Art, vol. 7, 1969, pp. 225-290.

3. Clough, G.W., and O'Rourke, T. D., "Construction Induced Movements of In-situ Walls", Proc. ASCE Specialty Conference on Design and Performance of Earth Retaining Structures, 1990, pp. 439-470.

4. Ou, C.Y., Hsieh, P.G., and Chien, S.C., "Use of Concrete Cross Walls to Reduce Movements Induced by Deep Excavation", Proc. of the World Congress on Advances in Civil, Environmental, and Materials Research (ACEM’ 12), Seoul, Korea, 2012, pp. 1962-1973.

5. Law, K.H.; Roslan, H., and Zubaidah, I., "3D Numerical Analysis and Performance of Deep Excavations in Kenny Hill Formation", Proc. $8^{\text {th }}$ European Conference on Numerical Methods in Geotechnical Engineering, Delft, The Netherlands, 2014, pp. 759-764.

6. Wood, J.H., "Earthquake-Induced Soil Pressures on Structures", Ph.D. Thesis, California Institute of Technology, California, USA, 1973.

7. Kitsis, V.G., Vlachakis, V.S., Athanasopoulos, G.A., and Athanasopoulos-Zekkos, A., "Seismic Thrust vs. Wall Inertia in Non-Yielding Retaining Walls Under Earthquake Loading: Synchronous or Asynchronous Action", Proc. of the International Foundations Congress and Equipment Expo, ASCE Geotechnical Special Publications 256, 2015, pp. 1513-1521.

8. Ahmad, A.A., Hefny, A.M., Mansour, M.F., and Mansour M.M., "Three-Dimensional Analysis of Rod El-Farag Subway Station, Greater Cairo Metro", Proc. $14^{\text {th }}$ International Conference on Structural and Geotechnical Engineering, Cairo, Egypt, vol. 10, 2015, pp. 1-16.

9. The Canadian Geotechnical Society, "Canadian Foundation Engineering Manual", $4^{\text {th }}$ edition, BiTech Publisher Ltd., 2006.

10. American Association of State Highway and Transportation Officials, "AASHTO LRFD Bridge Design Specifications", $4^{\text {th }}$ edition, Washington D.C., USA, 2007. 